\title{
Research of filter materials for dust fractioning
}

\author{
Vladimir Dmitrienko ${ }^{1 *}$, Stanislav Maslennikov ${ }^{1}$, and Aleksandr Bogomzov ${ }^{2}$ \\ ${ }^{1}$ Institute of service and business (branch) Don state technical University in town Shakhty of Rostov \\ region, Shevchenko street 147, 346500, Russia \\ ${ }^{2}$ Shakhty Road Institute (branch) YRSPU (NPI) named after M.I. Platov in town Shakhty of Rostov \\ region, lenin Square 1, 346500, Russia
}

\begin{abstract}
A special place in air pollution with dust emissions is occupied by the production of building materials, using large quantities of dispersed mineral substances as aggregates. The article is devoted to the study of hazardous dust fractions emission when assessing the dustiness of the working area for the production of concrete and reinforced concrete products, since the specific location and operation of the equipment complex is characterized by uneven dust formation in space and time. This reduces the efficiency of the aspiration systems. Based on the analysis of methods and means for assessing dustiness, the use of the gravimetric method is justified, however, to assess the content of the most dangerous dust particles for the human body with a size of 2.5 to 10 microns, a size separation of particles is required. Non-woven synthetic filter materials of various thicknesses and densities are investigated. It is proposed to carry out sampling in blocks with three filters from different filter materials. The studies were carried out with the help of a specially made portable complex. The most effective filter materials were determined with the help of microscopic analysis. The conducted calibration of the blower performance with an assessment of the measurement accuracy showed relatively small errors in the air sampling, which confirms the feasibility of assessing the dustiness of the filter blocks.
\end{abstract}

\section{Introduction}

One of the most important natural factors of human activity is atmospheric air, which affects life on the planet. Air pollution by highly dispersed solid particles is caused by natural and man-made processes [1-2].

In nature, air currents lift small particles from the surface of the earth and transport them over vast distances (pinkish dust from the Sahara colors snow even in the mountains of Central America), and small salt crystals from the surface of the oceans. When volcanoes erupt, large amounts of large dust particles are thrown into the air. Despite the huge emissions of

\footnotetext{
* Corresponding author: vadmitrienko@,rambler.ru
} 
dust, nature is capable of self-healing, but human activities significantly affect these processes negatively in most cases [1-2].

The constantly increasing rates of development and growth of production are accompanied by the intensive use of atmospheric air and, accordingly, its pollution. Dust formation is a very common hazardous and harmful industrial aspect, which causes a great environmental risk to the health of millions of people [3-4].

\section{Justification of the relevance}

High concentrations of dust are observed in the production processes of all industries. Mechanical processing of metals (turning, milling, drilling, grinding, polishing, etc.) is accompanied by the formation of waste in the form of solid particles (industrial dust), and aerosols when using lubricants.

In terms of the negative impact on the environment, metallurgy and the production of building materials occupy leading positions, and their dust and gas treatment systems annually capture hundreds of thousands of tons of dust [4-5].

An important place in machine-building production is occupied by the casting of blanks, which is usually carried out into sand molds. This is accompanied by an intensive release of highly dispersed dust into the working area of the premises. A large amount of dust and vapor emissions into the air are observed during electric welding, plasma and electric spark processing of metal, during grinding and products polishing of products [5].

The location of the equipment and the peculiarities of the implementation of technological processes in many industries do not fully allow for effective air purification in the working area, which requires the identification of areas with a dangerous concentration of dust [6]. The greatest danger to the human body is represented by dust particles with a size from 2.5 to 10 microns, which can penetrate deep into the respiratory system by exerting a fibrogenic effect [7-8]. Therefore, it is very important to evaluate the performance of aspiration systems both in production areas and in emission zones.

No less dangerous in terms of dust formation is the production of concrete and reinforced concrete products, using a large amount of mineral substances. The main areas of dust formation are the loading and unloading area of bulk materials, the loading area of the mixer.

Another source of dust formation is vibration platform. When vibrating, the excess of concrete mixture falls on the platform. When the next product vibrates, the concrete particles are crushed to a dusty state by the steel formwork elements.

The specifics of the equipment complex and the production technology of dry and finished concrete mix are such that the equipment is located on a large area and at different heights, so it is extremely difficult to ensure sufficiently effective air aspiration in the working area.

Thus, improving the methodology for assessing the content of small hazardous particles in the general dustiness of the working area to ensure labor safety at enterprises and the environmental situation in adjacent territories is a very important and urgent task.

\section{Methods and materials}

Analyzing modern research methods and measuring instruments for dust content, it can be noted that at present, many devices are produced to accurate control the concentration of dust in the air. However, such equipment is quite expensive and requires highly qualified personnel. Despite the capabilities of modern measuring instruments to monitor air pollution, the main method for periodic monitoring the dustiness of industrial premises remains the weight method, based on filtering air through a filter material with subsequent determination of the 
amount of deposited dust.

Since many production processes are characterized by cyclical operation, as well as the movement of technological equipment in plan and height, it is not possible to carry out effective aspiration. In this case, periodic monitoring of the level of dustiness is required to establish hazardous areas and develop measures to reduce the harmful effects on the body of working people. That is, it is necessary to assess the content of hazardous dust fractions of 2.5 - 10 microns [7-8].

Despite the widespread use of air dust control by the weight method, it has significant drawbacks: high labor intensity, the need to take into account the speed of air movement, the dependence of the accuracy of research results on the quality of filters and the qualifications of researchers; inability to assess the content of individual dust fractions [9-10]. It is also required to take into account wind directions, air temperature and humidity, which significantly affect the spread of dust through production facilities. That is, for an objective assessment of dust content, it is necessary to take measurements in different places and at different times, moreover, the interval between measurements should be minimal, since many processes are characterized by a change in the intensity of dust formation over time. This requires portable measuring equipment that allows repeated measurements at short intervals with stable characteristics.

An equally important factor is the quality of filter materials and their ability to filter out or pass particles of a certain size. Analysis of the materials most widely used in filters shows that they are mainly made from thin perchlorovinyl fibers using a special technology. The arrangement of the fibers in the materials is chaotic, therefore, it is impossible to reliably isolate particles of a certain size, which requires the selection of a filter material to isolate the most dangerous fractions of dust PM10 (less than 10 microns) and PM2.5 (2.5 microns).

Since in our town the most issues of organizing research are solved at enterprises for the production of building materials, the main research volume was carried out in the workshop for the production of reinforced concrete products. Microscopic analysis [11-15] (Fig. 1, 2) was used to estimate the size of particles passed through various filter materials, which shows that the distance between the fibers in the filters can differ significantly.
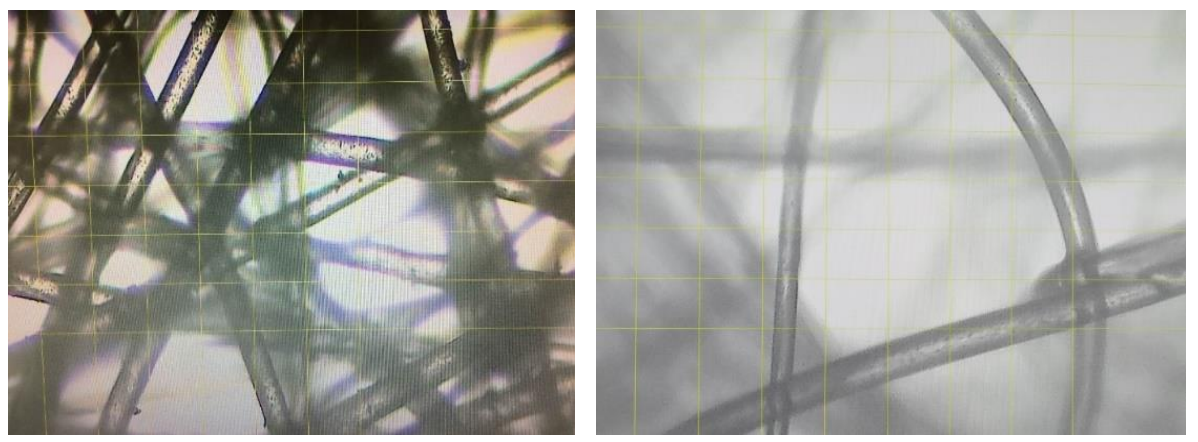

Fig. 1. Structure of non-woven synthetic filter material.

The studies were carried out with materials of the following classes: G2 with a density of $100 \mathrm{~g} / \mathrm{m}^{2}$; G3 with a density of $150 \mathrm{~g} \mathrm{~m}^{2}$; G4 with a density of $150 \mathrm{~g} / \mathrm{m}^{2}$; G4 with a density of $350 \mathrm{~g} / \mathrm{m}^{2}$; F5 with a density of $200 \mathrm{~g} / \mathrm{m}^{2}$; FTS 6 and FPP 15.

\section{Discussion of research results}

The highest degree of dust collection is provided by analytical filters AFA-VP-10 with the filtering material of Petryanov FPP 15, which are capable of retaining all particles up to 1 micron 
[16]. However, when the concentration of aerosols is more than $0.5 \mathrm{mg} / \mathrm{m}^{3}$, they quickly become contaminated due to the low dust holding capacity of the order of $100-150 \mathrm{~g} / \mathrm{m}^{2}$. Therefore, it is necessary to pre-filter dust particles larger than 10 microns.

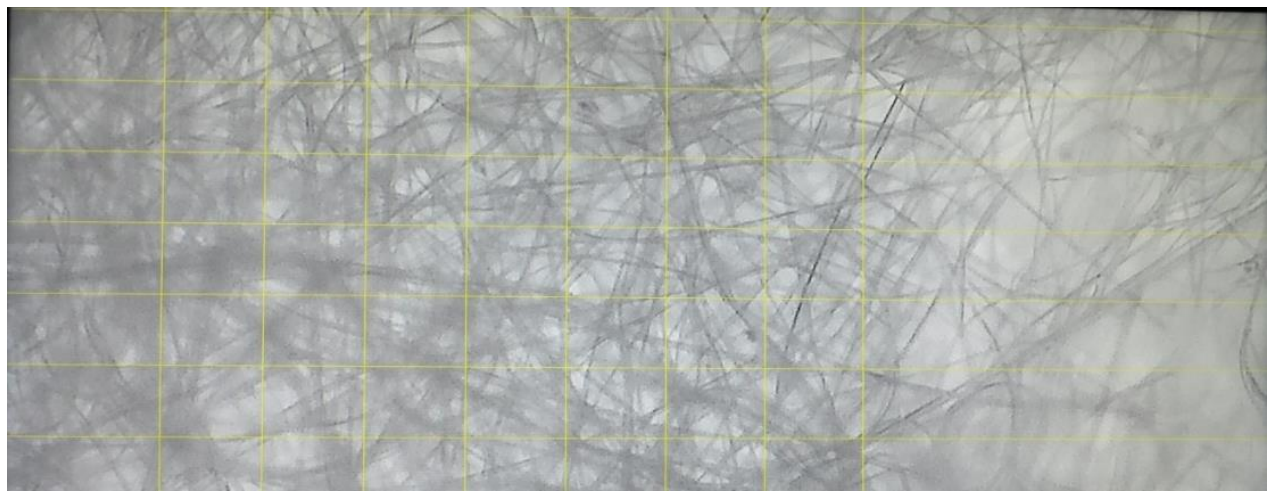

Fig. 2. Structure of the filter material FPP 15.

To separate PM10 fractions (less than 10 microns), 8 synthetic nonwoven materials of different thickness $(0.04-3.6 \mathrm{~mm})$ and density were tested. As a result, it was found that particles up to 20 microns in size are best retained by FT-350 (G4) material. Such a filter, has a high dust capacity, retains the depression linear change in the process of pollution longer, but many particles larger than 10 microns pass through it. Therefore, preference is given to the F5 material. Unlike the FT-350, it has a lower dust capacity, which will require limiting the time of air sampling.

To assess the content of the most hazardous dust fractions PM10 and PM2.5 in the air of the working area, it is necessary to use several filters when sampling: a grid with a grid size of $0.08 \mathrm{~mm}$ designed to separate fractions over 80 microns; a filter made of F5 material allowing to retain fractions of more than 10 microns, and a third filter made of Petryanov's material for cleaning dust particles from 10 to 1 microns. Moreover, in order to ensure the required accuracy and shortening of the test time, it is necessary to place the filters in a special block that excludes leakage between the filters.

In the process of experimental studies, it was found out that such a block is characterized by significant aerodynamic resistance, which reduces the air consumption during measurements, and, accordingly, requires an increase in the time for air sampling. Since many production processes are cyclical, the factors affecting dust formation may change, and the measured results will be incorrect. Therefore, when working with a filter unit, in order to shorten the measurement time intervals, it is necessary to ensure stable depression and sampling performance up to $300 \mathrm{dm}^{3} /$ min throughout the measurement period.

At present, there is a very large range of sampling devices with a flow rate of up to 300 $\mathrm{dm}^{3} /$ min of air for the gravimetric method of research. However, it was not possible to find a device with the necessary depression. Therefore, in the course of the experiments, a measuring set based on a car vacuum cleaner was developed, which makes it possible to provide the required performance and depression when sampling by blocks of three filter elements and grids that prevent deformation of filters.

To form blocks of polypropylene, boxes were made, in which there were five elements: a coarse mesh (mesh size $0.08 \mathrm{~mm})$; filter F5; fixing mesh $(0.2 \mathrm{~mm})$; fine filter FPP 15; fixing mesh $(0.2 \mathrm{~mm})$. The filters were separated by elastic rubber rings to prevent air overflow (Fig. 3). 


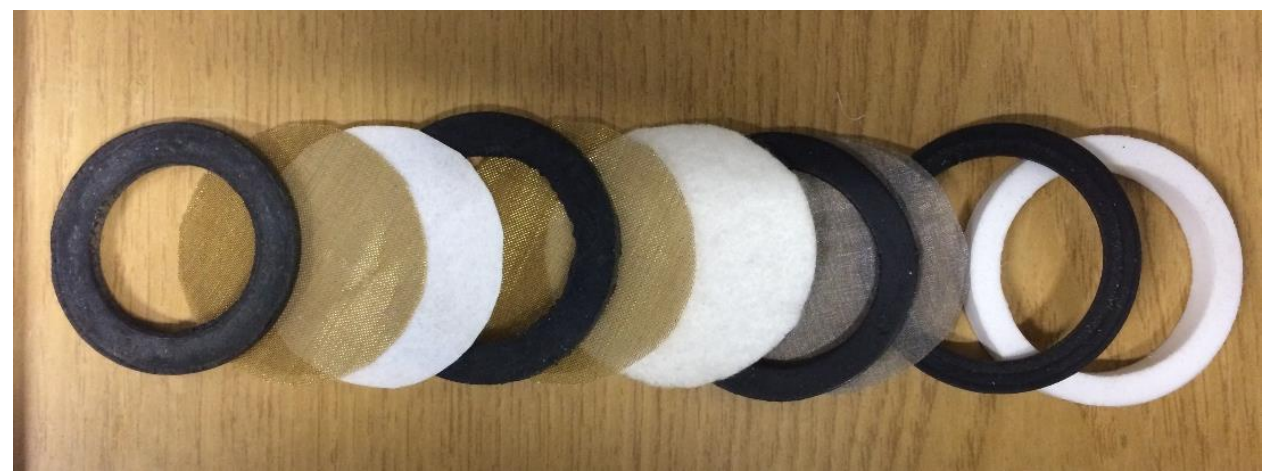

Fig. 3. Composition of the filter block.

A specially made nozzle on the blower for attaching the filter block made it possible to change the blocks prepared in the laboratory and to prepare the apparatus for taking a new sample in 30 - 40. The efficiency of separating dust fractions was investigated directly in the workshop during the production of concrete mixture. At this stage, a quantitative assessment of dusting was not assumed, therefore, the filters were not weighed, but the efficiency of dust separation was evaluated by microscopic analysis [17-18].

Evaluation of the particle size of captured dust by various materials was carried out by a measuring complex, including a microscope, a special video camera and a monitor, which made it possible to determine the size of particles retained by the filter on the monitor screen. For this, the microscope and the video camera grid were calibrated with a micrometer with a scale of $0.01 \mathrm{~mm}(10 \mu \mathrm{m})$.

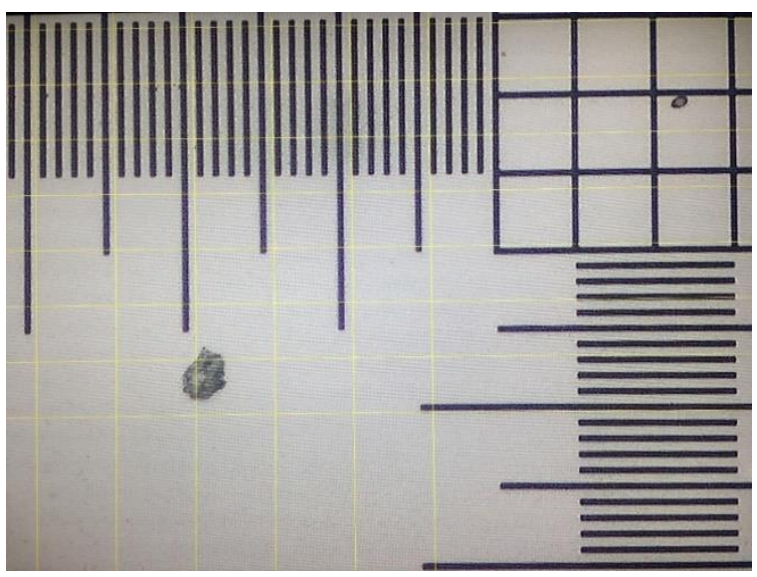

Fig. 4. Calibration of the camera grid with an object-micrometer (with dust particles of 40 and 10 microns).

Microscopic analysis showed that despite the distance between individual fibers up to 100 microns in the structure of even dense filters made of nonwoven materials, they are able to retain particles up to 10 microns and are suitable for fractionation of dust. The best results were shown by the filter material of the F5 class with a density of $200 \mathrm{~g} / \mathrm{m}^{2}$, characterized by a dense structure and a smaller distance between the fibers (Fig. 5).

For the separation of fractions less than 10 microns, the best material is FPP-15 (Petryanov's canvas), from which analytical filters are made. Filters made of such material have relatively low aerodynamic resistance. 


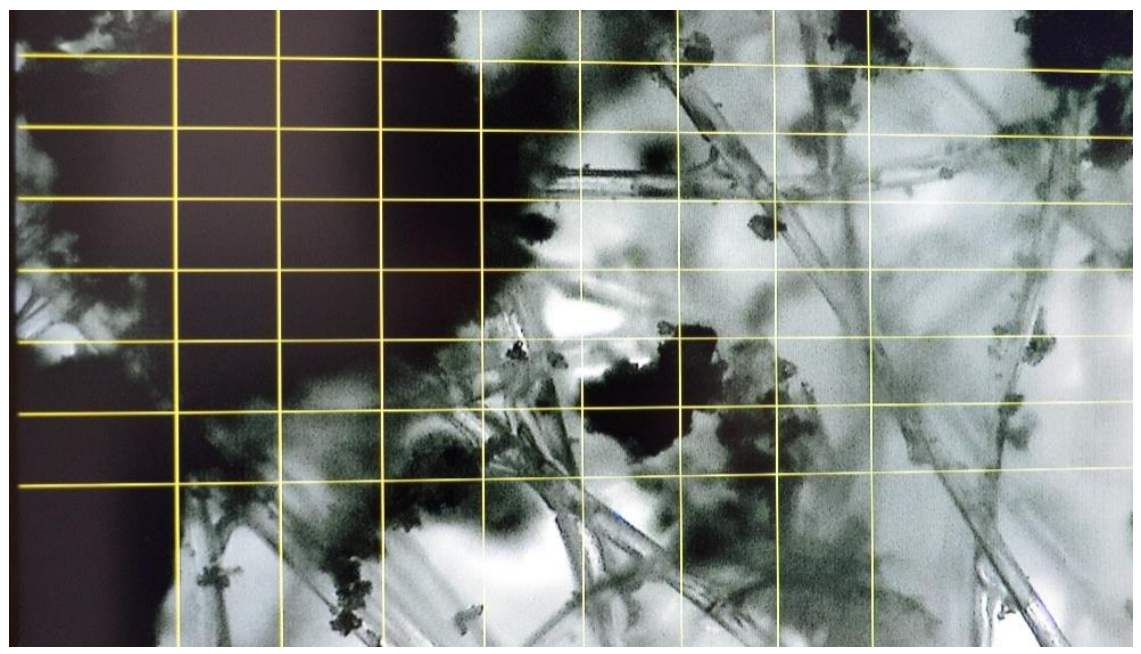

Fig. 5. Dust Particles on the fibers of the filter class F5.

With a large volume of air pumping, the accuracy of the measurements is very important, so the volume of the pumped air was calibrated for certain time intervals, which was carried out by the TG 4 electronic meter, taking into account the density and humidity of the air. To assess the adequacy of the studies and select the optimal sampling period, a set of measurements with a statistical accuracy assessment was performed.

The order of measurements was adopted as follows. Initially, the performance of the complex without filters was evaluated. The air sampling interval was 1, 2, 3 and 4 minutes. For each interval, from 5 to 8 measurements were made. Statistical evaluation showed the accuracy of air pumping volume at an interval of $1 \mathrm{~min}$. was $4.33 \%$, and at $4 \mathrm{~min} .1 .36 \%$.

Table 1. Results of air pumping volume measurements.

\begin{tabular}{|c|c|c|c|c|c|c|c|c|}
\hline 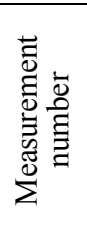 & 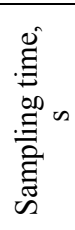 & 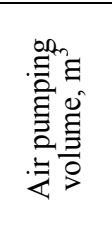 & 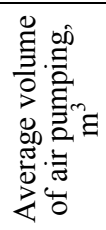 & 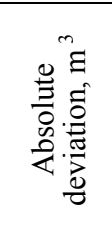 & 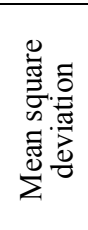 & 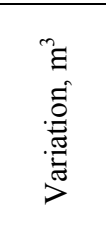 & 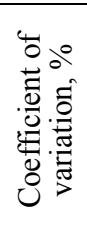 & 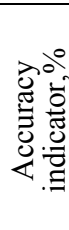 \\
\hline 1 & 1 & 0.0795 & 0.0789 & $-0,0006$ & 0.003 & 0.0079 & 3.354 & 6.24 \\
\hline 2 & & 0.0752 & & 0.0037 & & & & \\
\hline 3 & & 0.0804 & & -0.002 & & & & \\
\hline 4 & & 0.0821 & & -0.003 & & & & \\
\hline 5 & & 0.0742 & & 0.0047 & & & & \\
\hline 6 & & 0.0792 & & $-0,0003$ & & & & \\
\hline 7 & & 0.0816 & & -0.003 & & & & \\
\hline 8 & & 0.0790 & & $-0,0001$ & & & & \\
\hline 22 & 4 & 0.3172 & 0.3187 & 0.0015 & 0.002 & 0.0048 & 0.642 & 1.19 \\
\hline 23 & & 0.3216 & & -0.003 & & & & \\
\hline 24 & & 0.3208 & & -0.002 & & & & \\
\hline 25 & & 0.3168 & & 0.0019 & & & & \\
\hline 26 & & 0.3172 & & 0.0015 & & & & \\
\hline
\end{tabular}

Then the measurements are performed with the connected filter block. The volume counting error ranged from 6.24 to $1.19 \%$, with a variation of $7.9-1.2 \mathrm{dm} 3 / \mathrm{min}$. The results of the measurements and calculations at a temperature of $21^{\circ} \mathrm{C}$, a pressure of $756 \mathrm{~mm} \mathrm{Hg}$, and a relative 
humidity of $54 \%$ are shown in Table 1.

Studies have also shown that the blower performance without connecting filter units is $295 \mathrm{dm}^{3} / \mathrm{min}$, and after connecting the unit it decreases to $158 \mathrm{dm}^{3} / \mathrm{min}$, with a pressure drop across the filters on average $0.124 \mathrm{kPa}$, which does not exceed the limit values for the filters used. The air consumption was monitored by a counter with a counting accuracy of 0.1 $\mathrm{dm}^{3} / \mathrm{min}$, with an electronic timer recording the operating time of the blower motor. The maximum range of variation of air flow at the sampling time is $2 \mathrm{~min}$. it was $8.24 \mathrm{dm}^{3} / \mathrm{min}$, and $5.4 \mathrm{dm}^{3} / \mathrm{min}$ at 4 minutes. The maximum interval of variation of the air flow rate at a sampling time of 2 minutes was $8.24 \mathrm{dm}^{3} / \mathrm{min}$, and $5.4 \mathrm{dm}^{3} / \mathrm{min}$ at 4 minutes.

Thus, the studies carried out confirm the possibility of determining the content of hazardous fractions of dust PM10 and PM2.5 when examining the dustiness of the working area of various industries, which is necessary to determine the negative impact on workers and develop measures to reduce dust content in various sections of technological lines.

\section{Conclusion}

To assess the concentration of hazardous dust particles, it is advisable to take samples in blocks that include three filters. From the point of view of emission of hazardous fractions of dust PM10 and PM2.5, the most effective are: filter material of class F5 with a density of 200 $\mathrm{g} / \mathrm{m} 2$ and Petryanov's canvas.

Depending on the intensity of dust formation, the sampling time by the developed complex is determined by the dust capacity of the filtering materials and should be from 2 to 10 minutes. The content of hazardous dust fractions is defined as the ratio of the mass of dust on the analytical filter to the total mass of filtered dust, that is, the sum of the masses of particles on all filters and grids.

\section{References}

1. V.N. Azarov, N.A. Marinin, N.S. Barikaeva, T.N. Lopatina, Biosphere compatibility: man, region, technology, 1 (2013)

2. V. Bespalov, O. Gurova, N. Samarskaya, O. Paramonova, Web of Conferences, 135 (2019)

3. S.A. Koshkarev, M.A. Nikolenko, Economy. Business. Banks, 1 (14) (2016)

4. A.B. Strelyaeva, N.S. Barikaeva, E.A. Kalyuzhina, D.A. Nikolenko, Internet Bulletin of VolgGASU, 3 (34) (2014)

5. V.M. Kireev, Ecology and Industry of Russia, 12 (2012)

6. V.A. Minko, I.N. Logachev, I.N. Logachev, Publishing house of BSTU, 2 (2010)

7. V.N. Azarov, I.V. Tertishnikov, N.A. Marinin, Zhilishchnoe stroitel'stvo, 3 (2012)

8. V.N. Azarov, I.V. Tertishnikov, E.A. Kalyuzhina, N.A. Marinin, Bulletin of the Volgograd State University of Architecture and Civil Engineering. Ser.: Construction and architecture Issue, 25 (44) (2011)

9. P. Gargava, Aerosol and Air Quality Research, 14 (2014)

10. A. Ordonez, Archives of Environmental Contamination and Toxicology, 44 (2) (2003)

11. V.N. Azarov, S.A. Koshkarev, M.A. Nikolenko, Engineering Bulletin of the Don, 1 (2015)

12. S.A. Koshkarev, M.V. Belonozhko, Engineering Bulletin of the Don, 4 (2016)

13. N.M. Sergina, N.V. Neumerzhitskaya, Engineering Bulletin of the Don, 3 (2016) 
14. V.P. Batmanov, N.M. Sergina, D.S. Druzhinina, V.A. Evseeva, N.V. Neumerzhitskaya, Engineering Bulletin of the don, 1 (2017)

15. I.V. Sokolov-Petryanov, Nauka (Moscow, 2007)

16. A.P. Klimenko, Khimiya (Moscow, 1978)

17. V.N. Azarov, V.Yu. Yurkyan, N.M. Sergina, Legislative and applied Metrology, 4 (2001)

18. A.N. Bogomolov, D.V. Belogurov, A.V. Nesterenko, M.M. Tikhomirova, Engineering Bulletin of the don 4 (2016) 